\title{
PENGARUH FAKTOR EKSTERNAL IBU TERHADAP PEMBERIAN MP-ASI PADA BAYI USIA DIBAWAH 6 BULAN DI WILAYAH KERJA PUSKESMAS SIPORI-PORI KOTA TANJUNG BALAI
}

\author{
${ }^{1}$ Dian Zuiatna, ${ }^{2}$ Novy Ramini Harahap \\ ${ }^{1,2}$ Institut Kesehatan Helvetia, Jalan Kapten Sumarsono No. 107, Medan, Indonesia 20124, \\ email : zuiatna@yahoo.com
}

\section{Article History}

Dikirim, Desember $08^{\text {th }}, 2019$

Ditinjau, Desember $13^{\text {th }}, 2019$

Diterima,Desember $19^{\text {th }}, 2019$

\begin{abstract}
Background : UNICEF added that exclusive breastfeeding until a 6-month-old baby can prevent the deaths of 1.3 million children less than five months. Another problem in giving breast milk complementary food is timeliness. Objective : of this study was to determine the effect of maternal external factors on the provision of breast milk complementary food in infants aged less than 6 months at working area of SiporiPori Health Center, Tanjung Balai in 2018. Method: This research uses analytical survey method with cross sectional approach. The populations in this study were mothers who had babies aged over 6-12 months at Working Area of Sipori-Pori Health Center of Tanjung Balai as many as 373 mothers, with sampling using the Slovin formula so that the sample was 79 mothers who had infants aged over 6-12 months. Resulths: The statistical test results showed that there was an effect of family support, the role of health workers and social culture with the provision of breast milk complementary food for infants less than 6 months at working area of Sipori-Pori Health Center, Tanjung Balai in 2018. Conclusion: There is an influence of family support, the role of health workers, socio-culture with the provision of MP-ASI for infants under 6 months of age in the Puskesmas Sipori-Pori working area of Tanjung Balai in 2018. It is suggested to the health workers to be able to increase their role in providing information and motivation and increasing maternal knowledge about the benefits of exclusive breastfeeding and the right time in giving breast milk complementary food through counseling or leaflets by involving families closest to the mother.
\end{abstract}

Keywords: Family Support, Role of Health Officers, Social Culture, Breast Milk Complementary Food

\section{ABSTRAK}

Latar Belakang : UNICEF menambahkan bahwa pemberian ASI eksklusif sampai bayi berusia 6 bulan dapat mencegah kematian 1,3 juta anak berusia dibawah lima tahun. Masalah lainnya dalam pemberian MP-ASI yaitu ketepatan waktu. Tujuan: dalam penelitian ini adalah untuk megetahui Pengaruh Faktor Eksternal Ibu terhadap Pemberian MP-ASI pada Bayi Usia dibawah 6 Bulan di Wilayah Kerja Puskesmas Sipori-Pori Kota Tanjung Balai Tahun 2019. Metode: Penelitian ini menggunakan metode survei yang bersifat analitik dengan pendekatan cross sectional. Populasi pada penelitian ini adalah ibu yang memiliki bayi berusia diatas 6-12 bulan di Wilayah Kerja Puskesmas Sipori-Pori Kota Tanjung Balai yakni sebanyak $373 \mathrm{Ibu}$, dengan pegambilan sampel menggunakan rumus slovin sehingga sampel adalah 79 ibu yang memiliki bayi berusia diatas 6-12 bulan. Hasil: uji statistika menunjukan ada Pengaruh dukungan keluarga, peran petugas kesehatan dan soaial budaya dengan Pemberian MP-ASI pada Bayi Usia dibawah 6 Bulan di Wilayah Kerja Puskesmas Sipori-Pori Kota Tanjung Balai Tahun 2019. Kesimpulan: Ada pengaruh dukungan keluarga, Peran Petugas Kesehatan, sosial budaya dengan Pemberian MP-ASI pada Bayi Usia dibawah 6 bulan di Wilayah Kerja Puskesmas Sipori-Pori Kota Tanjung Balai tahun 2019. Disarankan Petugas kesehatan agar dapat meningkatkan perannya dalam memberikan informasi dan motivasi serta meningkatkan pengetahuan ibu tentang manfaat dan keuntungan pemberian ASI eksklusif dan waktu yag tepat dalam pemberian MP-ASI Dini melalui penyuluhan atau leaflet dengan melibatkan keluarga yang terdekat dengan ibu.

Kata Kunci : Dukungan Keluarga, Peran Petugas Kesehatan, Sosial Budaya, MP-ASI. 


\section{PENDAHULUAN}

Upaya pemeliharaan kesehatan anak ditujukan untuk mempersiapkan generasi yang akan datang yang sehat, cerdas, dan berkualitas serta untuk menurunkan angka kematian anak. Upaya pemeliharaan kesehatan anak dilakukan sejak janin masih dalam kandungan,dilahirkan, setelah dilahirkan, dan sampai berusia delapan belas tahun. Upaya kesehatan anak antara lain diharapkan mampu menurunkan angka kematian anak.

Pembangunan generasi yang cerdas serta berkualitas merupakan tanggung jawab seluruh komponen masyarakat khususnya ibu. Ibu mempunyai peran dan tanggung jawab melahirkan generasi yang cerdas berkualitas. Peningkatan kualitas manusia harus dipersiapkan sejak dalam kandungan dan saat persalinan hingga tumbuh kembangnya. Oleh karena itu kesejahteraan ibu dan anak perlu perhatian khusus. Bila kesehatan ibu setelah melahirkan baik, menyusui merupakan cara memberi makanan yang paling ideal untuk 4-6 bulan pertama sejak dilahirkan karena ASI dapat memenuhi kebutuhan gizi bayi. (1)

Menghasilkan generasi yang cerdas dan berkualitas, dalam Global Strategy for Infant and Young Child Feeding, World Health Organization (WHO) dan United Nations Children's Fund (UNICEF) merekomendasikan empat hal penting yang harus diperhatikan dalam pemberian makanan yang tepat untuk bayi dan anak dibawah usia dua tahun yaitu : pertama, memberikan air susu ibu kepada bayi segera dalam waktu 30 menit setelah bayi lahir. Kedua, memberikan hanya air susu ibu (ASI) saja atau pemberian ASI secara eksklusif sejak lahir sampai bayi berusia 6 bulan. Ketiga, memberikan makanan pendamping ASI (MP-ASI) yang tepat dan adekuat sejak 6 bulan sampai 24 bulan. Dan keempat, melanjutkan pemberian ASI sampai anak berusia 24 bulan atau lebih. (2)

Pengumpulan data yang dilakukakn Survei Demografi dan Kesehatan Indonesia (SDKI) 2012 tentang pemberian makanan pada bayi menunjukkan bahwa hanya $27 \%$ bayi umur 4-6 bulan mendapat ASI ekslusif (tanpa tambahan makanan atau minuman lain). Selain ASI, $8 \%$ bayi pada umur yang sama diberi susu lain dan $8 \%$ diberi air putih dam makanan tambahan dini. Pemberian ASI ekslusif kepada bayi berusia 4-6 bulan dalam SDKI 2012 lebih tinggi dibandingkan dengan hasil SDKI 2007 (masing-masing 27\% dan 17\%). (3)

Berdasarkan data Profil Kesehatan Provinsi Sumatera Utara Cakupan persentase bayi yang diberi ASI eksklusif dari tahun 2011-2015 cenderung menunjukkan peningkatan, dan cakupan pada tahun 2015 mengalami peningkatan yang cukup signifikan sebesar 10\% dibandingkan tahun 2014 dan telah mencapai target nasional yaitu $40 \%$. Namun di tahun 2016 terjadi penurunan yang tajam dibanding tahun 2015 dan tidak mencapai target nasional < dari 40\%. Kabupaten/Kota dengan pencapaian $\geq 40 \%$ untuk Kabupaten yaitu Labuhan Batu Utara (97.90\%), Samosir (94.8\%), Humbang Hasundutan (84.0\%), Simalungun (60.6\%), Dairi (55.7\%), Pakpak Bharat (50.5\%), Deli Serdang (47.1\%), Asahan (43.6\%), Labuhan Batu $(40.9 \%)$ dan untuk Kota yaitu Gunung Sitoli (84.5\%), Sibolga (46.7\%). Daerah dengan pencapaian $<10 \%$ yaitu Kota Medan (6.7\%), Tebing-Tinggi (7.4\%). (4)

Manfaat yang didapatkan dari pemberian ASI ekslusif, diantaranya dapat mempercepat penurunan angka kematian bayi dan sekaligus meningkatkan status gizi balita yang pada akhirnya akan meningkatkan status gizi masyarakat menuju tercapainya kualitas sumber daya manusia yang memadai. UNICEF menambahkan bahwa pemberian ASI eksklusif sampai bayi berusia 6 bulan dapat mencegah kematian 1,3 juta anak berusia dibawah lima tahun. (5)

Makanan pendamping ASI (MP-ASI) merupakan makanan tambahan yang diberikan kepada bayi setelah bayi berusia 4-6 bulan sampai bayi berusia 24 bulan. Selain makanan pendamping ASI, ASI harus tetap diberikan 
kepada bayi, paling tidak sampai berusia 24 bulan. Peranan makanan pendamping ASI sama sekali bukan untuk menggantikan ASI melainkan hanya melengkapi ASI. (6)

Masalah lainnya dalam pemberian MP-ASI yaitu ketepatan waktu. Kebiasaan pemberian makan yang tidak tepat, salah satunya pemberian makanan terlalu dini pada bayi usia kurang dari 6 bulan. Hal ini dapat berdampak pada gangguan sistem pencernaan bayi, seperti diare, muntah, sulit buang air besar, menyebabkan banyak infeksi, kenaikan berat badan berlebih, dan alergi terhadap salah satu zat gizi makanan. Oleh karena itu, pada saat bayi berusia 0-6 bulan pemberian ASI saja sudah cukup, dimana komposisi ASI ibu masih bisa mencukupi untuk pertumbuhan dan perkembangan bayi apabila ASI diberikan secara tepat dan benar sampai bayi berusia 6 bulan. (7)

Menurut Dirjen Gizi dan KIA masalah utama masih rendahnya penggunaan ASI di Indonesia yang akhirya membuat ibu memberika MP-ASI pada bayinya adalah faktor sosial budaya, kurangnya pengetahuan ibu hamil, keluarga dan masyarakat akan pentingnya ASI, serta jajaran petugas kesehatan yang belum sepenuhnya mendukung Peningkatan Pemberian ASI (PP-ASI) dengan cara tidak memberika Inisiasi Menyusu Dini (IMD). Masalah ini di perparah dengan gencarnya promosi susu formula dan kurangnya dukungan dari masyarakat, termasuk institusi yang memperkerjakan perempuan yang belum memberikan tempat dan kesempatan bagi ibu menyusui di tempat kerja (seperti ruang ASI). Keberhasilan ibu menyusui untuk terus menyusui bayinya sangat ditentukan oleh dukungan dari suami, keluarga, petugas kesehatan, masyarakat serta lingkungan kerja. (8)

Rendahnya pemberian ASI Eksklusif yang mengakibatkan pemberian MP-ASI dini pada bayi di Indonesia umumnya di sebabkan oleh 2 faktor yakni faktor internal yang meliputi rendahnya pengetahuan serta sikap ibu tentang ASI Eksklusif serta faktor eksternal yang meliputi kurangnya dukungan keluarga, masih kuatnya budaya dan kurangnya dukungan petugas kesehatan untuk melaksanakan kebijakan pemerintah tentang pemberian ASI Eksklusif. (9)

Berdasarkan hasil survei awal yang dilakukan oleh peneliti di Wilayah Kerja Puskesmas Sipori-Pori pada bulan Juli 2018 terdapat 10 orang ibu yang memiliki bayi berusia 6-12 bulan. Dari 10 ibu tersebut, sebanyak 9 ibu yang memberikan MP-ASI dini dan hanya 1 ibu yang memberikan ASI Eksklusif serta MP-ASI pada waktu yang tepat yaitu > 6 bulan dengan alasan kebiasaan masyarakat di Wilayah Kerja Puskesmas, terutama orang tua dan mertua yang memberikan makanan tambahan seperti madu, larutan gula dan pisang dan air tajin kepada bayinya dengan alasan bayi akan kelaparan bila hanya diberikan ASI.

Suami sebagai kepala keluarga biasanya menuruti kebiasaan tersebut dengan berbagai alasan, antara lain kurangnya pemahaman tentang ASI eksklusif atau takut tidak patuh kepada orang tua dan mertua. Kelancaran menyusui juga memerlukan kondisi kesetaraan antara keluarga terutama suami dan istri tetapi kenyataannya hingga saat ini masih sangat sedikit keinginan suami untuk ikut berperan serta dalam perawatan anaknya termasuk mendukung aktivitas menyusui.

Berdasarkan dari uraian diatas, maka saya sebagai penulis tertarik untuk melakukan penelitian dengan judul "Pengaruh Faktor Eksternal Ibu terhadap Pemberian MP-ASI pada Bayi Usia dibawah 6 Bulan di Wilayah Kerja Puskesmas Sipori-Pori Kota Tanjung Balai Tahun 2018"

\section{METODE}

Penelitian ini dilakukan di Wilayah Kerja Puskesmas Sipori-Pori Kota Tanjung Balai dengan alasan masih tingginya ibu yang memberikan MP-ASI dini dikarenakan sosial budaya, kurangnya dukungan keluarga, dan kurangnya peran petugas kesehatan. Penelitian dimulai pada bulan Januari sampai dengan 
April Tahun 2019.

Desain penelitian yang digunakan adalah survei analitik. Survei analitik yang di lakukan pada penelitian ini menggunakan rancangan pendekatan bedah lintang (cross sectional). Cross sectional ialah suatu penelitian untuk mempelajari dinamika korelasi antara faktor resiko dengan faktor efek, dengan cara pendekatan, observasi atau pengumpulan data sekaligus pada satu waktu yang sama. (28)

Populasi pada penelitian ini adalah ibu yang memiliki bayi berusia diatas 6-12 bulan di Wilayah Kerja Puskesmas Sipori-Pori Kota Tanjung Balai yakni sebanyak 373 Ibu.

Sampel merupakan bagian populasi yang akan diteliti atau sebagian jumlah dari karakteristik yang dimiliki oleh populasi. Sampel dalam penelitian ini menggunakan menggunakan rumus Slovin karena dalam penarikan sampel, jumlahnya harus representative agar hasil penelitian dapatdigeneralisasikan. Maka sampel dalam penelitian ini sebanyak 79 ibu yang memiliki bayi usia diatas 6-12 bulan di Wilayah Kerja Puskesmas Sipori-Pori. Sampel yang diambil berdasarkan teknik sampling cluster yang merupakan penggambilan sampel dimana elemen-elemen sampelnya merupakan elemen (cluster). Teknik ini disebut juga teknik kelompok atau rumpun yang dilakukan dengan jalan memilih sampel yang didasarkan pada clusternya bukan individunya. (29

Data primer adalah data yang langsung diperoleh dari responden. Data Primer yang digunakan dalam penelitian ini adalah kuesioner untuk mengukur variable sosial budaya, dukungan keluarga, peran petugas kesehatan dan MP-ASI dini.

Teknik pengumpulan data diambil dengan data sekunder yaitu dengan melihat data ibu yang memiliki bayi diatas $6-12$ bulan pada bulan Juli 2018 yang diperoleh dari Wilayah Kerja Puskesmas Sipori-Pori Kota Tanjung Balai

Analisa bivariat dilakukan apabila telah dilakukan analisis univariat diatas, akan diketahui karakteristik atau distribusi setiap variabel. Analisa bivariat yang dilakukan untuk mengetahui hubungan (korelasi) antara variabel bebas dan variabel terikat.

Untuk membuktikan adanya hubungan yang signifikan antara variabel bebas dengan varibel terikat digunakan uji statistik Chisquare, pada batas kemaknaan perhitungan statistik $p$-value $(0,05)$. Apabila hasil perhitungan menunjukkan nilai $\mathrm{p}<p$-value $(0,05)$ maka dikatakan (Ho) ditolak, artinya kedua variabel secara statistik mempunyai hubungan yang signifikan. Kemudian untuk menjelaskan adanya asosiasi (hubungan) antara variabel terikat dengan variabel bebas digunakan analisis tabulasi silang.

Uji statistik multivariat digunakan untuk menguji hubungan simultan lebih dari dua variabel. Sama seperti statistik univariat, statistik multivariat juga dapat dibedakan menjadi uji parametrik dan nonparametrik. Penelitian ini menggunakan uji regresi logistik. Dimana analisis regresi logistik adalah salah satu pendekatan model matematis yang digunakan untuk menganalisis hubungan satu atau beberapa variabel independen dengan sebuah variabel dependen kategori yang bersifat dikotom/binary. Perbedaan antara regresi linier dengan regresi logistik terletak pada jenis variabel dependennya. Regresi linier digunakan apabila variabel dependennya numerik, sedangkan regresi linier digunakan pada data yang dependennya berbentuk kategori yang dikotom.

Regresi logistik adalah bagian dari analisis regresi yang digunakan ketika variabel dependen (respon) merupakan variabel dikotomi. Variabel dikotomi biasanya hanya terdiri atas dua nilai, yang mewakili kemunculan atau tidak adanya suatu kejadian yang biasanya diberi angka 0 atau 1 . Regresi logistik (logistic regression) sebenarnya sama dengan analisis regresi berganda, hanya variabel terikatnya merupakan dummy variabel (0 dan 1). Regresi logistik ini digunakan untuk menguji apakah probabilitas terjadinya variabel terikat dapat diprediksi dengan 
variabel bebasnya.

\section{HASIL}

Analisis Bivariat: Berdasarkan tabulasi silang dapat diketahui bahwa dari 35 responden $(44,3 \%)$ yang memiliki dukungan keluarga mendukung terdapat 20 responden $(25,3 \%)$ yang memberikan MP-ASI Dini dan 15 responden $(19,0 \%)$ yang tidak memberikan MP-ASI Dini. Sedangkan dari 44 responden $(55,7 \%)$ yang memiliki dukungkan keluarga tidak mendukung terdapat 40 responden (50,6\%) yang memberikan MP-ASI Dini dan 4 responden $(5,1 \%)$ yang tidak memberikan MPASI Dini. Hasil uji statistik Chi-square dengan melihat pada Fisher Exact antara variabel dukungan keluarga dengan pemberian MP-ASI pada bayi dibawah 6 bulan menunjukkan nilai $p$ value 0,001 , dimana nilai $p$ value $<\alpha=0,05$ maka ada hubungan antara dukungan keluarga dengan pemberian MP-ASI paa bayi dibawah 6 bulan. Tabulasi silang dapat diketahui bahwa dari 14 responden $(17,7 \%)$ yang mengatakan peran petugas kesehatan baik terdapat 4 responden $(5,1 \%)$ yang memberikan MP-ASI Dini dan 10 responden $(12,7 \%)$ yang tidak memberikan MP-ASI Dini. Sedangkan dari 65 responden $(82,3 \%)$ yang mengatakan peran petugas kesehatan kurang terdapat 56 responden $(70,9 \%)$ yang memberikan MP-ASI Dini dan 9 responden $(11,4 \%)$ yang tidak memberikan MP-ASI Dini. Hasil uji statistik Chi-square dengan melihat pada Fisher Exact antara variabel peran petugas kesehatan dengan pemberian MP-ASI pada bayi dibawah 6 bulan menunjukkan nilai $p$ value 0,000 dimana nilai $p$ value $<\alpha=0,05$ maka ada hubungan antara peran petugas kesehatan dengan pemberian MP-ASI paa bayi dibawah 6 bulan. Hasil tabulasi silang dapat diketahui bahwa dari 16 responden (20,3\%) yang memiliki sosial budaya positif terdapat 5 responden $(6,3 \%)$ yang memberikan MP-ASI Dini dan 11 responden $(13,9 \%)$ yang tidak memberikan MP-ASI Dini. Sedangkan dari 63 responden $(79,7 \%)$ yang memiliki sosial budaya negatif terdapat 55 responden $(69,6 \%)$ yang memberikan MP-ASI Dini dan 8 responden $(10,1 \%)$ yang tidak memberikan MP-ASI Dini. Hasil uji statistik Chi-square dengan melihat pada Fisher Exact antara variabel sosial budaya dengan pemberian MPASI pada bayi dibawah 6 bulan menunjukkan nilai $p$ value 0,000 dimana nilai $p$ value $<\alpha=$ 0,05 maka ada hubungan antara sosial budaya dengan pemberian MP-ASI pada bayi dibawah 6 bulan.

Tabel .1. Tabulasi Silang antara Dukungan Keluarga dengan Pemberian MP-ASI pada Bayi Usia dibawah 6 Bulan di Puskesmas Sipori-Pori Tanjung Balai Tahun 2019.

\begin{tabular}{|c|c|c|c|c|c|c|c|}
\hline \multirow{3}{*}{ Variabel } & \multicolumn{6}{|c|}{$\begin{array}{l}\text { MP-ASI pada Bayi Usia dibawah } \\
6 \text { Bulan }\end{array}$} & \multirow[t]{2}{*}{ Signifikan } \\
\hline & \multicolumn{2}{|c|}{ MP-ASI Dini } & \multicolumn{2}{|c|}{ Tidak MP-ASI Dini } & \multicolumn{2}{|c|}{ Total } & \\
\hline & $\mathbf{f}$ & $\%$ & f & $\%$ & $\mathbf{F}$ & $\%$ & \multirow{4}{*}{0,001} \\
\hline Dukungan Keluarga & & & & & & & \\
\hline Mendukung & 20 & 25,3 & 15 & 19,0 & 35 & 44,3 & \\
\hline Tidak Mendukung & 40 & 50,6 & 4 & 5,1 & 44 & 55,7 & \\
\hline \multicolumn{8}{|c|}{ Peran Petugas Kesehatan } \\
\hline Baik & 4 & 5,1 & 10 & 12,7 & 14 & 17,7 & \multirow[t]{2}{*}{$\mathbf{0 , 0 0 0}$} \\
\hline Kurang & 56 & 70,9 & 9 & 11,4 & 65 & 82,3 & \\
\hline \multicolumn{7}{|l|}{ Sosial Budaya } & \multirow{3}{*}{$\mathbf{0 , 0 0 0}$} \\
\hline Positif & 5 & 6,3 & 11 & 13,9 & 16 & 20,3 & \\
\hline Negatif & 55 & 69,6 & 8 & 10,1 & 63 & 79,7 & \\
\hline
\end{tabular}


Analisis Multivariat : Berdasarkan hasil uji statistik Binary Logistic pada tabel 4.18 diatas menunjukkan bahwa dari 3 variabel independen (dukungan keluarga, peran petugas kesehatan, sosial budaya) yang diuji hasilnya, seluruh variabel yang mempunyai pengaruh yang signifikan terhadap MP-ASI Dini. Dukungan Keluarga memiliki nilai signifikan 0,019 , dimana $p$ value $<0,05$, dimana Ho ditolak dan $\mathrm{Ha}$ diterima yang berarti ada hubungan antara kegemukan dengan MP-ASI Dini di Wilayah Kerja Puskesmas Sipori-Pori. Dukungan Keluarga memiliki nilai Exp (B) sebesar 5,747 (1,388- 24,679), hal ini menunjukkan bahwa responden yang memiliki memiliki dukungan keluarga yang tidak mendukung memiliki peluang 5,747 kali lebih besar menderita memberikan MP-ASI Dini dibandingkan dengan responden yang memiliki dukungan keluarga mendukung.

Peran Petugas Kesehatan memiliki nilai signifikan 0,028 , dimana $p$ value $>0,05$, dimana Ho diterima dan Ha ditolak yang berarti ada hubungan antara peran petugas kesehatan dengan MP-ASI Dini di Wilayah Kerja Puskesmas Sipori-Pori. Peran Petugas Kesehatan memiliki nilai Exp (B) sebesar 5,858 (1,208- 28,399), hal ini menunjukkan bahwa responden yang mengalami mendapat peran petugas kesehatan kurang memiliki peluang 5,858 kali lebih besar memberikan MP-ASI Dini dibandingkan dengan responden yang mendapat peran petugas kesehatan baik.

Sosial Budaya memiliki nilai signifikan 0,033, dimana $p$ value $>0,05$, dimana Ho ditolak dan Ha diterima yang berarti ada hubungan antara sosial budaya dengan MP-ASI Dini di Wilayah Kerja Puskesmas Sipori-Pori. Sosial Budaya memiliki nilai Exp (B) sebesar 5,101 (1,14522,721), hal ini menunjukkan bahwa responden yang memiliki sosial budaya negative memiliki peluang 5,101 kali lebih besar memberikan MP-ASI Dini dibandingkan dengan responden yang sosial budayanya positif.

Tabel .2. Hasil Variable in the Equation (Pendugaan Parameter)

\begin{tabular}{|c|c|c|c|c|c|c|c|c|}
\hline \multirow{2}{*}{ Variabel } & \multirow{2}{*}{$\boldsymbol{B}$} & \multirow{2}{*}{ S.E. } & \multirow{2}{*}{ Wald } & \multirow{2}{*}{$d f$} & \multirow{2}{*}{ Sig. } & \multirow{2}{*}{$\operatorname{Exp}(B)$} & \multicolumn{2}{|c|}{ 95\% C.I.for $\mathrm{EXP}(B)$} \\
\hline & & & & & & & Lower & Upper \\
\hline $\begin{array}{l}\text { Dukungan } \\
\text { Keluarga }\end{array}$ & 1,749 & 0,744 & 5,531 & 1 & 0,019 & 5,747 & 1,338 & 24,679 \\
\hline $\begin{array}{l}\text { Peran Petugas } \\
\text { Kesehatan }\end{array}$ & 1,768 & 0,805 & 4,818 & 1 & 0,028 & 5,858 & 1,208 & 28,399 \\
\hline Sosial Budaya & 1,629 & 0,762 & 4,570 & 1 & 0,033 & 5,101 & 1,145 & 22,721 \\
\hline
\end{tabular}

\section{PEMBAHASAN}

\section{Pengaruh Dukungan Keluarga dengan Pemberian MP-ASI pada Bayi Usia} dibawah 6 bulan : Dukungan Keluarga memiliki nilai signifikan 0,019 , dimana $p$ value $<0,05$, dimana Ho ditolak dan $\mathrm{Ha}$ diterima yang berarti ada hubungan antara kegemukan dengan MP-ASI Dini di Wilayah Kerja Puskesmas Sipori-Pori. Dukungan Keluarga memiliki nilai Exp (B) sebesar 5,747 (1,388-24,679), hal ini menunjukkan bahwa responden yang memiliki memiliki dukungan keluarga yang tidak mendukung memiliki peluang 5,747 kali lebih besar menderita memberikan MP-ASI Dini dibandingkan dengan responden yang memiliki dukungan keluarga mendukung.

Sejalan dengan penelitian yang dilakukan oleh Daulat Ginting, dengan judul pengaruh karakteristik, faktor internal dan eksternal ibu terhadap pemberian mp-asi dini pada bayi usia $<6$ bulan di Wilayah Kerja Puskesmas Barusjahe Kabupaten Karo Provinsi Sumatera Utara. Hasil penelitian Hasil penelitian menunjukkan bahwa dukungan keluarga dengan nilai $p<0,001$, peran petugas kesehatan dengan nilai $\mathrm{p}<0,001$ dan sosial budaya dengan nilai $\mathrm{p}<0,001$ mempengaruhi 
pemberian MP-ASI Dini pada bayi usia <6 bulan (nilai $\mathrm{p}<0,05)$. (10)

Dukungan suami maupun keluarga lain dalam rumah akan sangat membantu berhasilnya seorang ibu untuk menyusui. Perasaan ibu yang bahagia, senang, perasaan menyayangi bayi, memeluk, mencium dan mendengar bayinya menangis akan meningkatkan pengeluaran ASI. (23) Seorang ibu yang mendapatkan dukungan dari suami dan anggota keluarga lainnya akan meningkatkan pemberian ASI kepada bayinya. Sebaliknya dukungan yang kurang maka pemberian ASI menurun. Menyusui bukan semata-mata tanggung jawab ibu yang melahirkan bayinya saja. Mennyusui bisa dikatakan sebagai hasil tim antara ibu-bayiayah dan lingkungan (keluarga). (24)

Dukungan keluarga mempunyai hubungan dengan suksesnya pemberian ASI Eksklusif kepada bayi karena dengan adanya dukungan maka memotivasi ibu memberikan ASI saja kepada bayinya sampai usia 6 bulan, kondisi fisiologis ibu menjadi baik dan dapat memperlancar produksi ASI kepada ibu dan mempersiapkan nutrisi yang seimbang kepada ibu. (23) Peranan keluarga dalam memberikan dukungan kepada ibu sangat dominan berhubungan dengan perilaku ibu. Banyak ibu yang tinggal berdekatan dengan keluarganya seperti orang tua dan mertua. Praktek pemberian ASI diketahui oleh budaya dan norma yang berkembang di kalangan anggota keluarga, rekan, dan masyarakat secara umum. Peranan keluarga terhadap berhasil atau tidaknya ibu memberikan ASI eksklusif sangat besaar terlebih bila ibu yang tinggal serumah dengan orang tua. Kebiasaan memberikan susu formula terlalu dini telah dilakukan turun menurun dan tidak menimbulkan masalah. Dukungan keluarga atau orang tua merupakan faktor eksternal yang paling besar pengaruhnya karena berhubungan dengan rasa percaya diri ibu.

Menurut asumsi peneliti, terdapat hubungan yang signifikan antara dukungan keluarga dengan pemberian MP-ASI Dini, hal ini berhubungan dengan hubungan baik dengan keluarga. Ketika keluarga bersikap positif dan mendukung pemberian ASI eksklusif seperti menyarankan ibu makanan yang bernutrsi, makanan yang memperlancar ASI seperti daun katuk serta membantu ibu mengenai kendala yang dialami nya selama menyusui serta terus menyarankan ibu untuk tetap memberikan ASI hingga usia bayi 6 bulan. Hubungan yang baik juga dapat mendukung ibu memberikan ASI eksklusif karena dengan hubungan yang baik maka psikologis ibu pada masa postpartum pun baik pula sehingga produksi ASI ibu tidak mengalami kendala dan ibu memberikan MPASI tepat waktu.

Pengaruh Peran Petugas dengan Pemberian MP-ASI pada Bayi Usia dibawah 6 bulan : Peran Petugas Kesehatan memiliki nilai signifikan 0,028 , dimana $p$ value > 0,05, dimana Ho diterima dan $\mathrm{Ha}$ ditolak yang berarti ada hubungan antara peran petugas kesehatan dengan MP-ASI Dini di Wilayah Kerja Puskesmas Sipori-Pori. Peran Petugas Kesehatan memiliki nilai Exp (B) sebesar 5,858 (1,208- 28,399), hal ini menunjukkan bahwa responden yang mengalami mendapat peran petugas kesehatan kurang memiliki peluang 5,858 kali lebih besar memberikan MP-ASI Dini dibandingkan dengan responden yang mendapat peran petugas kesehatan baik.

Penelitian yang dilakukan oleh Daulat Ginting, dengan judul pengaruh karakteristik, faktor internal dan eksternal ibu terhadap pemberian mp-asi dini pada bayi usia $<6$ bulan di Wilayah Kerja Puskesmas Barusjahe Kabupaten Karo Provinsi Sumatera Utara. Hasil penelitian Hasil penelitian menunjukkan bahwa dukungan keluarga dengan nilai $\mathrm{p}<0,001$, peran petugas kesehatan dengan nilai $\mathrm{p}<0,001$ dan sosial budaya dengan nilai $\mathrm{p}<0,001$ mempengaruhi pemberian MP-ASI Dini pada bayi usia $<6$ bulan (nilai $\mathrm{p}<0,05$ ). (10)

Peran petugas kesehatan terutama dalam memberikan promosi adalah melalui pendidikan kesehatan. Peran petugas kesehatan sangat 
penting dalam melindungi, meningkatkan, dan mendukung usaha pemberian ASI eksklusif. Sebagai individu yang bertanggung jawab dalam gizi bayi dan perawatan kesehatan, petugas kesehatan memiliki posisi yang dapat memengaruhi organisasi dan fungsi pelayanan kesehatan ibu baik sebelum, selama maupun setelah kehamilan dan persalinan. Bidan adalah petugas kesehatan yang terlibat pada perawatan selama kehamilan sampai bayi lahir. Petugas kesehatan harus dapat menginformasikan kepada ibu agar memberikan ASI eksklusif kepada bayinya dengan menjelaskan manfaat dan komposisi ASI dan waktu pemberian MP-ASI yang tepat. (24)

Peran petugas kesehatan terhadap pemberian ASI eksklusif ini juga sangat penting tidak hanya bagi bayi tetapi juga bagi ibu yang menyusui. Petugas kesehatan yang terlibat pada perawatan selama kehamilan sampai bayi lahir biasanya adalah seorang dokter dan bidan. Bidan merupakan ujung tombak kesehatan masyarakat. Peran petugas kesehatan adalah promosi melalui pendidikan kesehatan. Petugas kesehatan harus dapat menginformasikan kepada ibu agar memberikan ASI eksklusif kepada bayinya dengan menjelaskan manfaat dan komposisi ASI dibandingkan dengan susu formula dan tidak memfasilitasi bayi baru lahir dengan susu formula.

Menurut asumsi peneliti, terdapat hubungan yang signifikan antara peran petugas kesehatan dengan pemberian MP-ASI Dini, karena ketika petugas kesehatan berperan dengan baik maka akan bermanfaat menambah informasi pada ibu sehingga pengetahuan ibu mengenai ASI eksklusif pun bertambah yang berdampak ibu memiliki sikap positif dan memberikan ASI eksklusif dan tidak memberikan MP-ASI Dini. Sebaliknya, ketika petugas kesehatan tidak berperan dengan baik maka ibu mungkin saja mendapat informasi dari orang-orang yag lebih tua atau tetangga, yang terkadang malah bertentangan dengan pemberian ASI eksklusif. Salah satu bukti secara nyata sikap dan tindakan petugas kesehatan dalam mendukung ibu memberikan ASI eksklusif kepada bayinya, misalnya dengan tidak memfasilitasi bayi yang baru lahir dengan susu formula, pelaksanaan IMD, penyuluhan agar ibu tetap terus menyusui anaknya meskipun pada hari pertama ASI belum lancer.

Pengaruh Sosial Budaya dengan Pemberian MP-ASI pada Bayi Usia dibawah 6 bulan : Sosial Budaya memiliki nilai signifikan 0,033 , dimana $p$ value $>0,05$, dimana Ho ditolak dan $\mathrm{Ha}$ diterima yang berarti ada hubungan antara sosial budaya dengan MP-ASI Dini di Wilayah Kerja Puskesmas Sipori-Pori. Sosial Budaya memiliki nilai Exp (B) sebesar 5,101 (1,14522,721), hal ini menunjukkan bahwa responden yang memiliki sosial budaya negative memiliki peluang 5,101 kali lebih besar memberikan MP-ASI Dini dibandingkan dengan responden yang sosial budayanya positif.

Penelitian yang dilakukan oleh Daulat Ginting, dengan judul pengaruh karakteristik, faktor internal dan eksternal ibu terhadap pemberian mp-asi dini pada bayi usia $<6$ bulan di Wilayah Kerja Puskesmas Barusjahe Kabupaten Karo Provinsi Sumatera Utara. Hasil penelitian Hasil penelitian menunjukkan bahwa dukungan keluarga dengan nilai $p<0,001$, peran petugas kesehatan dengan nilai $\mathrm{p}<0,001$ dan sosial budaya dengan nilai $\mathrm{p}<0,001$ mempengaruhi pemberian MP-ASI Dini pada bayi usia $<6$ bulan (nilai $\mathrm{p}<0,05$ ). (10)

Permasalahan utama dalam pemberian MP-ASI Dini adalah sosial budaya antara lain kurangnya kesadaran akan pentingnya ASI, pelayanan kesehatan yang belum sepenuhnya mendukung, gencarnya promosi susu formula. Adapun kebiasaan yang tidak mendukung pemberian ASI adalah memberikan makanan/minuman setelah bayi lahir seperti madu, air kelapa, nasi papah, pisang dan memberikan susu formula sejak dini, orang tua dan keluarga juga masih menyediakan dan menganjurkan pemberian susu formula dan 
adanya kepercayaan kalau menyusui dapat merusak bentuk payudara.

Sosial budaya mencakup pengetahuan, kepercayaan, norma, hukum, adat-istiadat, kemampuan-kemampuan, serta kebiasaan. Kebiasaan dalam rumah tangga, tetangga, anjuran orang tua sangat mempengaruhi ibu tidak memberikan ASI Eksklusif. Meskipun masyarakat mengetahui bahwa kebiasaankebiasaan yang dilakukannya seperti memberikan makanan tambahan pada bayinya dapat berakibat buruk, tetapi karena pengaruh tersebut mereka tetap melakukannya. Peran kebudayaan terhadap kesehatan masyarakat adalah dalam memberntuk, mengatur dan mempengaruhi tindakan atau kegiatan individu-individu suatu kelompok sosial untuk memenuhi berbagai kebutuhan kesehatan. Sehingga ketika persepsi tentang kesehatan ataupun penyebab sakit sudah berbeda sekali dengan konsep medis, tentunya upaya mengatasinya juga berbeda di sesuaikan dengan keyakinan ataupun kepercayaankepercayaan yang sudah dianut secara turunmenurun sehingga lebih banyak menimbulkan dampak-dampak yang merugikan bagi kesehatan. (22)

Menurut asumsi peneliti sosial budaya dianggap berpengaruh terhadap pemberian MP-ASI Dini karena sosial budaya mencakup pengetahuan, kepercayaan, norma, hukum, adat-istiadat, kemampuan-kemampuan, serta kebiasaan. Merubah perilaku yang berisi kepercayaan adat-istiadat, kemampuankemampuan, serta kebiasaan ini sangat membutuhkan waktu dan cara strategis. Pemberian informasi yang benar mengenai ASI eksklusif saja tidak cukup untuk mengubah sosial budaya di dalam masyarakat. Ketika ibu mendapat informasi yang cukup mengenai ASI eksklusif, dan memiliki pengetahuan yang baik pula, asumsi dari orang-orang sekitar, kebiasaan atau adatistiadat dari orang-orang tua yang masih di terapkan dapat mempengaruhi pengetahuan ibu tersebut sehingga tidak menerapkan ASI eksklusif. Mayoritas masyarakat di Puskesmas
Sipori-Pori adalah Melayu yang memiliki adatistiadat dalam kelahiran yang salah satunya sangat bertentangngan dengan pemberian MPASI Dini yaitu pemberian madu yang di oleskan ke bibir bayi yang baru lahir dengan anggapan bahwa madu tersebut dapat membuat jika bayi tumbuh dewasa kelak akan merasakan hal-hal yang manis dalam hidupnya, akan berbicara yang manis dan tidak kasar. Pemberian pisang pada bayi dibawah 6 bulan dengan anggapan bahwa bayi akan lapar ketika hanya dengan ASI saja. Pemberian MPASI instan dengan anggapan usia diatas 4 bulan sudah layak diberikan makanan tambahan sehinggga mekipun ibu memiliki pengetahuan yang baik tentang ASI Eksklusif, pengaruh dari orang-tua dan mertua yang meminta ibu untuk mengikuti adat-istiadat karena adanya rasa patuh kepada orang tua maka ibu tetap memberikan MP-ASI Dini.

\section{KESIMPULAN}

Ada pengaruh dukungan keluarga, peran petugas kesehatan, social budaya dengan Pemberian MP-ASI pada Bayi Usia dibawah 6 bulan di Wilayah Kerja Puskesmas Sipori-Pori Kota Tanjung Balai tahun 2019.

Petugas kesehatan yang menolong persalinan juga diharapkan melakukan inisiasi menyusu dini dalam satu jam pertama kelahiran sebagai langkah awal dalam keberhasilan pemberian ASI eksklusif dan MP-ASI tepat waktu. Perlu penelitian lebih lanjut untuk mengetahui variabel lain, yang diduga berhubungan dengan pemberian MP-ASI pada Bayi Usia dibawah 6 bulan dengan jumlah sampel yang lebih banyak sehingga lebih representatif.

\section{UCAPAN TERIMA KASIH}

Terima kasih peneliti ucapkan kepada Bapak H. Yadi Arianto, SKM, M.Kes selaku Kepala Puskesmas Sipori-pori Kota Tanjungbalaiyang telah memberikan izin kepada peneliti untuk melakukan penelitian dan telah menerima peneliti dengan baik selama dalam melakukan penelitian 


\section{DAFTAR PUSTAKA}

1. Setyaningsih A. Hubungan Karakteristik Ibu Dengan Pemberian Mp Asi Dini Pada Bayi Usia 0-6 Bulan Di Posyandu Warna Sari Desa Glonggong Nogosari Boyolali. 2013;

2. World Health Organization. Infant and Young Child Feeding [Internet]. 2018 [cited 2018 Jul 12]. Available from: http://www.who.int/news-room/factsheets/detail/infant-and-young-childfeeding

3. BPS, BKKBN, Kemenkes. SDKI. Survei Demogr dan Kesehat Indones. 2013;266.

4. Profil Dinas Kesehatan Provinsi Sumatera Utara. Dinas Kesehatan Provinsi Sumatera Utara. 2017;1.

5. Waryana. Gizi Reproduksi. Yogyakarta: Pustaka Rihama;

6. Arizki W. Hubungan Pengetahuan Ibu Tentang MP-ASI Terhadap Pemberian MP-ASI Pada Bayi 0-6 Bulan Di Puskesmas S.Parman Banjarm MP-ASI. 2013;

7. Dahlan. Hubungan Antara Status Pekerjaan dengan Pemberian MP-ASI di Kecamatan Peukan Bada Kabupaten Aceh Besar provinsi DI Aceh. 2012;

8. Muthmainnah N. Hubungan Pekerjaan Ibu dan Dukungan Suami dengan Keberhasilan Pemberian ASI ekslusif pada Bayi Usia 0-6 Bulan di Dusun II Desa Bandar Setia. 2015.

9. Yulianah Pn, Burhanuddin Bahar AS. Hubungan Antara Pengetahuan, Sikap Dan Kepercayaan Ibu Dengan Pemberian Asi Eksklusif Di Wilayah Kerja Puskesmas Puskesmas Bonto Cani Kabupaten Bone Tahun 2013. 2013;1-13.

10. Ginting. D. Pengaruh Karakteristik, Faktor Internal dan Eksternal Ibu Terhadap Pemberian MP-ASI Dini pada Bayi Usia <6 Bulan di Wilayah Kerja Puskesmas Barusjahe Kabupaten Karo Provinsi Sumatera Utara. 2012;

11. Lestari E, Widiastuti YP, Kunsianah, Qomariyah N. Faktor-Faktor Yang
Mempengaruhi Perilaku Ibu Dalam Pemberian MP-ASI Dini Di Desa Jungsemi Kecamatan Kangkung Kabupaten Kendal. 2015;218-9.

12. Heryanto E. Faktor-Faktor yang Berhubungan dengan Pemberian Makanan Pendamping ASI Dini. J Aisyah J Ilmu Kesehat [Internet]. 2017;2(2):141. Available from: https://ejournal. stikesaisyah.ac.id/index.php/jika/article/ view/EH

13. Depkes RI. Manejemen Laktasi. Direktorat Jendral Bina Kesehatan Masyarakat. 2013.

14. Yuliarti N. Keajaiban Asi Makanan Terbaik Untuk Kesehatan Kecerdasan Dan Kelincahan Si Kecil. Yogyakarta: ANDI; 2013.

15. Prasetyono D sunar. Buku pintar ASI Esklusif pengenalan, pratik, dan kemanfaatan-kemanfaatanya. Jogjakarta: DIVA press;

16. Kodrat L. Dahsyatnya ASI \& Laktasi Untuk Kecerdasan Buah Hati Anda. Yogyakarta: MEDIA BACA; 2012.

17. Sjahmien M. Pemeliharaan Gizi Bayi dan Balita. Jakarta: Bhratara Karya Aksara; 2013.

18. Handy F. Panduan Menyusui \& Makanan Sehat Bayi. Jakarta: Pustaka Bunda;

19. Cadwell, Turner M. Buku Saku Manajemen Laktasi. Jakarta: EGC;

20. Lewis. Menyiapkan Makanan Bayi. Jakarta: Esensi Erlangga Group; 2012.

21. Wargiana R, Susumaningrum LA, Rahmawati I. Hubungan Pemberian MPASI Dini dengan Status Gizi Bayi Umur 0-6 Bulan di Wilayah Kerja Puskesmas Rowotengah Kabupaten Jember ( The Correlation between Giving Early Complementary Breastfeeding and Level Baby Nutrition 0-6 Month in Work Area of Rowotengah C. J Pustaka Kesehat. 2013;1(1):6-11.

22. Marimbi H. Tumbuh Kembang, Status Gizi \& Imunisasi Dasar Pada Balita. Yogyakarta: Nuha Medika; 2015. 
23. Haryono R, Setianingsih S. Manfaat ASI Eksklusif Untuk Buah Hati Anda. Yogyakarta: Gosyeng Publising; 2014.

24. A. M. Inisiasi Menyusui Dini, Asi Eksklusif da Managemen Laktasi. Jakarta: Trans Info Media; 2013.

25. Sitorus SBM. Pengaruh Dukungan Keluarga dan Faktor Sosial Budaya Terhadap Pemberian Asi Eksklusif Pada Bayi 0-6 Bulan di Wilayah Kerja Puskesmas Sukaraya Kecamatan Pancurbatu Kabupaten Deli Serdang. 2016;(X):1-5.

26. Proverawati A, Rahmawati E. Kapita Selekta ASI Dan Menyusui. Yogyakarta: Nuha Medika; 2013.

27. Nainggolan D. Hubungan Karakteristik Ibu, Dukungan Keluarga, dan Peran Petugas Kesehatan dengan Pemberian ASI Eksklusif di Kecamatan Siatas Barita Kabupaten Tapanuli Utara. 2014;

28. Muhammad I. Panduan Penyusunan Karya Tulis Ilmiah. Bandung: Cipta Pustaka Media Perintis; 2015.

29. Muhammad I. Pemanfaatan SPSS dalam Penelitian Sosial dan Kesehatan. Bandung: Cipta Pustaka Media Perintis; 2015. 